OPEN ACCESS

Edited by:

Johanna Jackson,

Eli Lilly, United Kingdom

Reviewed by:

Esther Stoeckli,

University of Zurich, Switzerland

Fritz Rathjen,

Max Delbrück Center for Molecular

Medicine, Helmholtz Association of

German Research Centers (HZ),

Germany

*Correspondence: Hermann Aberle aberle@hhu.de

Received: 14 February 2019 Accepted: 20 May 2019 Published: 06 June 2019

Citation:

Aberle H (2019) Axon Guidance and Collective Cell Migration by Substrate-Derived Attractants. Front. Mol. Neurosci. 12:148. doi: 10.3389/fnmol.2019.00148

\section{Axon Guidance and Collective Cell Migration by Substrate-Derived Attractants}

\author{
Hermann Aberle* \\ Functional Cell Morphology Lab, Heinrich Heine University Duesseldorf, Duesseldorf, Germany
}

Neurons have evolved specialized growth structures to reach and innervate their target cells. These growth cones express specific receptor molecules that sense environmental cues and transform them into steering decisions. Historically, various concepts of axon guidance have been developed to better understand how axons reach and identify their targets. The essence of these efforts seems to be that growth cones require solid substrates and that major guidance decisions are initiated by extracellular cues. These sometimes highly conserved ligands and receptors have been extensively characterized and mediate four major guidance forces: chemoattraction, chemorepulsion, contact attraction and contact repulsion. However, during development, cells, too, do migrate in order to reach molecularly-defined niches at target locations. In fact, axonal growth could be regarded as a special case of cellular migration, where only a highly polarized portion of the cell is elongating. Here, I combine several examples from genetically tractable model organisms, such as Drosophila or zebrafish, in which cells and axons are guided by attractive cues. Regardless, if these cues are secreted into the extracellular space or exposed on cellular surfaces, migrating cells and axons seem to keep close contact with these attractants and seem to detect them right at their source. Migration towards and along such substrate-derived attractants seem to be particularly robust, as genetic deletion induces obvious searching behaviors and permanent guidance errors. In addition, forced expression of these factors in ectopic tissues is highly distractive too, regardless of the pattern of other endogenous cues. Thus, guidance and migration towards and along attractive tissues is a powerful steering mechanism that exploits affinity differences to the surroundings and, in some instances, determines growth trajectories from source to target region.

Keywords: axon guidance, collective cell migration, attraction, Sidestep, Netrin, SDF1

\section{INTRODUCTION-A SHORT HISTORICAL PERSPECTIVE OF AXON GUIDANCE}

Postmitotic neurons polarize and send out axons that make a series of sequential pathway choices to reach distant target cells. The molecular regulation of these outgrowth, steering and recognition processes became a fundamental topic in neuroscience during the last century. Ever since the discovery of the growth cone ("cono de crecimiento") by Ramon y Cajal, neuroscientists 
wondered about the molecular nature of axon navigation and target recognition (Ramon Y Cajal, 1890; Raper and Mason, 2010).

In the cellular and histological era, anatomical studies and transplantation/extirpation experiments were the driving force for predominantly mechanical interpretations of nerve growth, based on the demonstration of a substrate requirement by Harrison or the concept of "contact action" along topographic features by Weiss (Harrison, 1907, 1910; Weiss, 1941). Sperry, on the other hand, developed an independent hypothesis, proclaiming that neuronal networks organize on the basis of specific "cytochemical affinities" (Sperry, 1963). Subsequent investigations of developing sensory nerves in grasshopper limb buds formed the idea that sheathing cells (glia) at stereotyped positions constitute a "system of signposts" with directive activities (Bate, 1976). Similar spatial arrangements were detected by Singer and co-workers in the late 1970s. Their histological studies in developing newts revealed gaps between neural progenitors of the ventricular zone that became filled with axon bundles over time, giving rise to the "blueprint hypothesis," i.e., axons migrate along preformed "channels" that serve as mechanical guides (Singer et al., 1979; Gottlieb, 1980). Pre-existing substrate routes were also deduced from transplanting eyes to non-optic regions, including tails, of tadpoles, as ectopic axons followed specific pathways to the brain (Katz and Lasek, 1978, 1979). However, mechanical factors and physical features alone cannot be entirely responsible for wiring highly complex nervous systems with billions of nerve connections.

In fact, the upcoming genetic and molecular era helped to uncover biochemical cues controlling axon guidance. Staining grasshopper embryos with monoclonal antibodies showed that axon tracks in the central nervous system (CNS) express specific surface molecules that label subsets of axonal pathways for selective recognition by outgrowing growth cones (Goodman et al., 1982). These identification tags were proposed to be recognized selectively by adequately specified growth cones, giving rise to the "labeled pathways hypothesis" that was strongly supported by steering decisions of identifiable axons and direct experimental manipulations such as single cell ablations (Goodman et al., 1984).

The surge of recombinant DNA technology and the execution of genetic screens in the 1980s and 1990s led to the identification of conserved guidance molecules that function as secreted ligands or transmembrane receptors and attract or repel axons (Tessier-Lavigne and Goodman, 1996; Dickson, 2002). Thus, the bottom line from this historical perspective is that growing nerves require a substrate that is selected based on the steering information of an exquisite set of extracellular proteins. In the following, I will continue predominantly with substrate-derived attractants, molecules secreted from or presented on cells that simultaneously serve as a preferred growth substrate. For more general aspects of axon guidance, in particular, repulsion, see excellent reviews by Kolodkin and Tessier-Lavigne (2011) and Seiradake et al. (2016).

\section{SUBSTRATE RECOGNITION AND AXON SORTING BY ADHESIVE INTERACTIONS}

Growth cones indeed carefully choose their substrates and are very well able to discriminate between different surfaces both in tissue culture plates (Letourneau, 1975b) and in selective choice assays testing target from non-target cells (Bonhoeffer and Huf, 1980). In patterned plastic dishes with different molecules in grid-like arrangements, chick sensory neurons preferentially elongated on substrates with increased adhesiveness (Letourneau, 1975a). Growth cones explored but did not cross onto non-adhesive areas (Letourneau, 1975a; Oakley and Tosney, 1993). In fact, differential adhesion guided axons into narrow channels with increased adhesiveness (Hammarback et al., 1985). However, other studies found no or little correlations between the relative substrate adhesiveness and growth rates or the molecular composition of substrates and preferential growth cone selection, respectively (Lemmon et al., 1992).

Nevertheless, direct contact to a substrate is clearly necessary for sustained axon growth, and the formation of local adhesion plaques might influence guidance decisions. Single filopodia in pioneering axons have been shown to trigger growth cone turning of chick sensory neurons towards laminin-coated beads (Kuhn et al., 1998). Here, growth cones grew out on a uniform fibronectin substrate and encountered a laminin-coated bead held in place by optical trapping using a laser tweezer. Filopodia explored the bead before forming an initial stable contact, which then attracted the entire growth cone (Kuhn et al., 1998). Similar observations have been made in Grasshopper embryos in vivo where turning of pioneering growth cones in the Til sensory pathway towards guidepost cells was initiated by filopodial contacts (O'Connor et al., 1990). Importantly, differential expression of a single Cadherin adhesion protein was necessary and sufficient for sorting axonal processes in the fly visual system (Schwabe et al., 2014). Similar to groups of cells that sort themselves out based on differential adhesion, for example during the formation of embryonic compartment boundaries (Amack and Manning, 2012), establishing adhesive contacts to a preferred substrate could be an important guidance principle.

\section{AXONS AND MIGRATING CELLS ARE SUBJECT TO SIMILAR STEERING PRINCIPLES}

It is interesting to note that axon growth could be regarded as a specialized form of cell migration. By leaving the soma in place and extending only a portion of the cell, axonal growth might utilize principles established at the leading edge of migrating cells (von Philipsborn and Bastmeyer, 2007). Similar to growing axons, migrating cells, either as individuals or cohesive groups, depend on substrates and extracellular steering cues. During Drosophila development, for example, border cells, peripheral glial cells or tracheal cells, all show migration patterns along stereotypic pathways (Pocha and Montell, 2014). The tracheal 
system develops from clusters of coherent cells that invaginate from the ectoderm into the interior of the embryo (Figure 1A). These cells are all tightly connected with each other by adherence junctions. Specialized cells at the leading tip sprout motile filopodia, which recognize and follow local sources of the attractive factor Branchless $(\mathrm{Bnl})$, a member of the fibroblast growth factor (FGF) family (Affolter and Caussinus, 2008). Bnl is expressed in non-tracheal cells consistently located ahead of elongating branches and is recognized by the Breathless (Btl) receptor expressed in trachea (Sutherland et al., 1996; Caussinus et al., 2008). Simultaneous labeling of Bnl source cells and Btl receiving cells revealed a dynamically moving signal source that directed the growth of tracheal branches (Du et al., 2017). Tip cells hence follow Bnl-expressing cells and thereby elongate the branch. Imaging Bnl-GFP fusion proteins during imaginal disc development demonstrated that Btl-expressing tracheal cells directly contact Bnl-GFP-expressing source cells (Sohr et al., 2019). Due to adhesive intercellular junctions that connect tip cells and stalk cells, the entire elongating branch resembles somehow, metaphorically speaking, an "axon-like" structure.

In fact, there are similar tip cell-guided collective migration events in vertebrates, too. Migration of cohesive cells has been observed during sprouting of blood vessels, invasion of cancer cells or development of neural crest cells, to name a few examples (Friedl and Gilmour, 2009; Szabó and Mayor, 2018). The attractants are not always known, but the chemokine
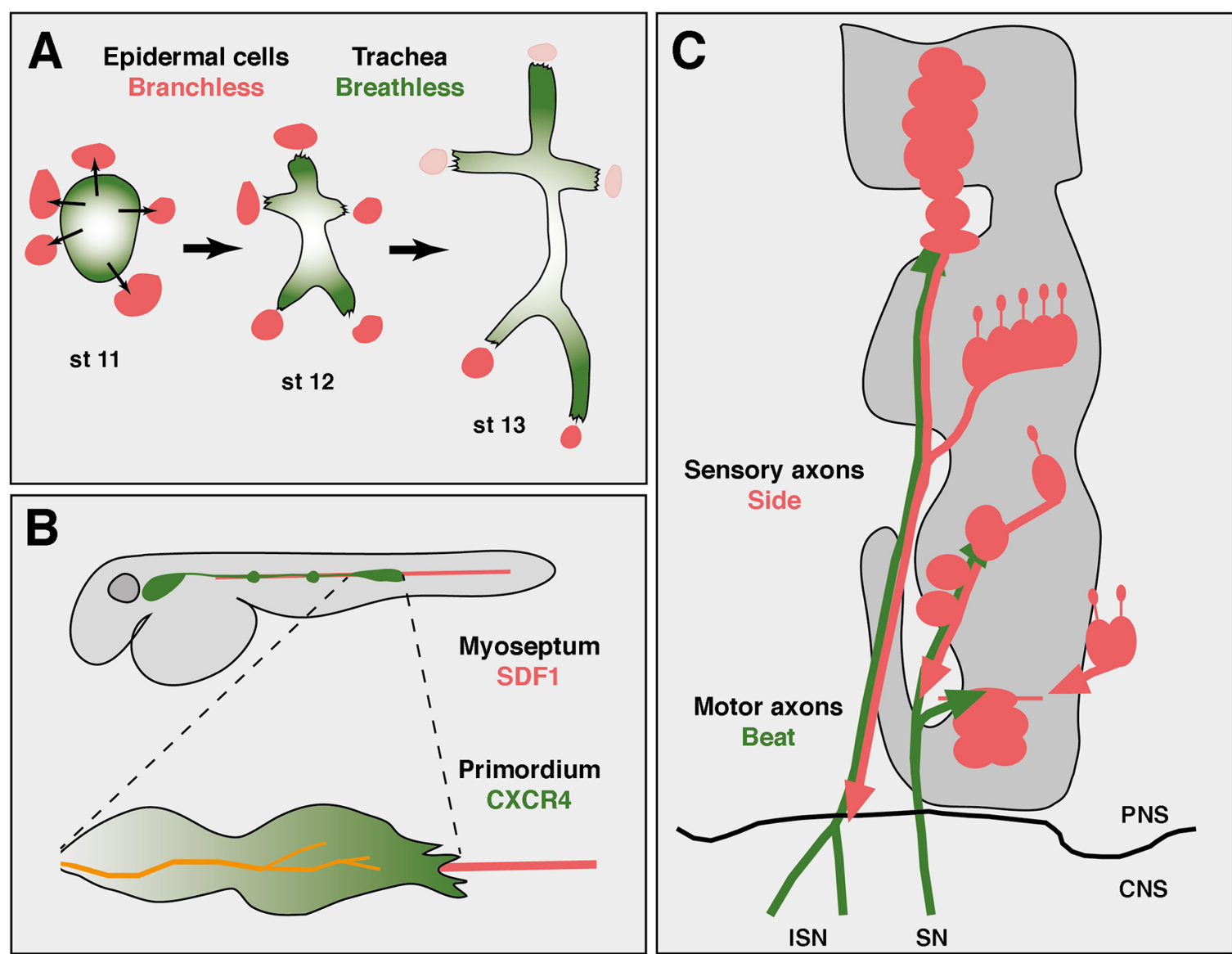

FIGURE 1 | Axon guidance and cell migration towards and along attractive substrates. (A) Collective cell migration during development of the tracheal system in an abdominal hemisegment of Drosophila embryos. Simplified scheme showing the development of tracheal branches from a cluster of coherent precursors (green) in the dorsal epidermis. At developmental stage 11 (st 11), five cell clusters outside the tracheal anlage express Branchless (Bnl, red), which induces tracheal outgrowth (thin arrows). At stage 12, Breathless-expressing tracheal cells recognize and grow towards Bnl-expressing cells. Retreat of the Bnl source extends these initial branches. At stage 13, the dorsal-most branches reach their final positions at the dorsal midline and segmental borders, where Bnl expression eventually ceases (pink). Individual cells are not resolved in this scheme. Thick arrows indicate developmental progression. Anterior is left, dorsal is up. (B) Axon "towing" by a migrating cell cluster during zebrafish development. The lateral line primordium (green) migrates from a placode near the head to its final destination in the tail, strictly following the horizontal myoseptum (red). Two neuromasts have already been deposited along its path (green dots). Leading cells in the primordium sprout long filopodia and express CXCR4 receptors that recognize the attractant SDF1 emanating from the substrate. The lateral line nerve (orange) co-migrates with the primordium and connects neuromasts to the brain. (C) Axon guidance along attractive substrates. Scheme of motor axon development in Drosophila embryos at stage 14. Motor axons of the intersegmental (ISN) and segmental (SN) nerve express Beaten path (green) and fasciculate with Sidestep-expressing sensory axons (red). Developing muscle fields do not express Sidestep at this stage and are outlined in gray. The central nervous system (CNS)/PNS boundary is marked (black line). Not to scale. Schemes according to Sutherland et al. (1996), Gilmour et al. (2004) and Siebert et al. (2009). 
SDF1 (stromal cell-derived factor 1, also called CXCL12), has been shown to play an important role as a substrate-derived attractant for migratory cells during vertebrate development, particularly in zebrafish (Doitsidou et al., 2002; Chalasani et al., 2003; Knaut et al., 2003). SDF1 is expressed along the horizontal myoseptum, amongst other regions, and directs the migration of the posterior lateral line primordium and its accompanying nerve (Figure 1B; Haas and Gilmour, 2006). The primordium consists of a placode-derived cell cluster and deposits small cell aggregates in regular intervals that develop into neuromasts, mechanosensory organs detecting water flow in fishes (Ghysen and Dambly-Chaudière, 2004).

Interestingly, the lateral line nerve, which innervates these neuromasts, maintains a central position in the advancing primordium and strikingly appears to co-migrate with it, a phenomenon that has been called "nerve towing" (Weiss, 1941; Gilmour et al., 2004). The primordium expresses the chemokine receptor CXCR4 that detects SDF1 (Peled et al., 1999; David et al., 2002). It is most strongly activated in tip cells at the leading edge and required for migration along SDF1 secreting substrates (Haas and Gilmour, 2006). Interruptions in the linear expression pattern or forced expression of SDF1 in ectopic tissues caused extremely abnormal migration patterns followed by erroneous distribution of neuromasts (Haas and Gilmour, 2006). Similarly, mutations in CXCR4 largely abolished the migration of the primordium and thus outgrowth of the lateral line nerve (Gilmour et al., 2004), indicating that SDF-1 ligands emanating from the horizontal myoseptum delineate a robust trajectory that guides the primordium, which in turn "pulls" the lateral line nerve from its origin in a cranial ganglion to the tail. While the molecular connections of the growth cone to cells in the primordium are unknown, this unusual guidance principle demonstrates a strict dependence on a substratederived attractant.

Although SDF1 is a small and secreted protein, and thus difficult to detect in tissues, it might not necessarily act over long distances but might locally enrich in the extracellular matrix as a short-range cue. First, it is stunning that, in vivo and in different organisms, attracted cells usually follow the dynamic expression domains of SDF1 very tightly (Doitsidou et al., 2002; Knaut et al., 2003). In this respect, it is important to note that in a developing embryo several tissues secrete SDF1 at the same time. For example, during zebrafish somitogenesis, SDF1 is expressed in somites, specific regions in the head and along the border of the trunk mesoderm (Doitsidou et al., 2002). Unrestricted diffusion from all these sources at the same time should distribute SDF1 widely in the body cavity, possibly interfering with gradient formation. But SDF1 signals from different sources do not seem to interfere with each other during normal development. Indeed, neither migrating cells nor axons are confused or distracted from neighboring SDF1 sources, indicating that its acts rather locally (Lewellis and Knaut, 2012; Lewellis et al., 2013). In addition, immunohistochemical stainings using specific polyclonal antibodies show cellular but not extracellular patterns in the mouse brain (Miller et al., 2005). Furthermore, the distribution of fluorescent SDF1-fusion proteins expressed from genomic BAC clones closely resembled that observed by in situ hybridizations (Bhattacharyya et al., 2008). It is possible that widespread diffusion is prevented by receptor-mediated clearance (Boldajipour et al., 2008) or proteoglycan trapping (Reiss et al., 2002). Taken together, available evidence supports the possibility of local SDF1 accumulations in the extracellular matrix of expressing cells.

\section{AXON GUIDANCE ALONG MARKED SUBSTRATES}

Similar cell surface enrichments might also apply for Netrinexpressing cells. Secreted Netrin proteins are generally believed to attract commissural axons over long distances towards and across the midline. In the developing spinal cord, Netrin 1 is expressed at highest levels in the floor plate, and hypomorphic gene-trap mice first revealed that it is required there to cross the midline (Serafini et al., 1996). Removing Netrin 1 completely, in null mutant mice, resulted in an even stronger phenotype, with commissural axons rarely crossing the midline at all (Bin et al., 2015; Yung et al., 2015). Interestingly, conditional knockouts lacking Netrin1 selectively in floor plate cells of the hindbrain showed surprisingly little crossing defects. In contrast, deletions in neuronal progenitors of the ventricular zone prevented midline crossing, and the phenotypes were indistinguishable from null mutants. Netrin1 was detected on neuronal processes extending to the pial surface suggesting that commissural axons detect the protein there locally (Dominici et al., 2017; Varadarajan et al., 2017). Latest experiments in the spinal cord similarly found evidence for a haptotactic function of Netrins but chemoattraction from the floor plate also played a role (Moreno-Bravo et al., 2019; Wu et al., 2019). In fact, evidence for short-range function of Netrins was also obtained in vitro and in invertebrates. Netrin-coated beads triggered traction forces and reoriented spinal commissural axons by adhesive interactions in vitro (Moore et al., 2009). In addition, experiments in Drosophila showed that a membrane-tethered form of endogenous NetrinB rescued commissure formation indicating that Netrin secretion was not required (Brankatschk and Dickson, 2006). Future experiments should, therefore, address the exiting question if Netrins function as substratederived attractants.

Direct contact-dependent adhesion to an attractive cue was recently demonstrated in $C$. elegans and underlies the construction of a sensory circuit responding to harsh mechanical stimuli (Chen et al., 2019). Primary dendrites of the enormous PVD neuron adhere to and migrate along axons of the ALA interneuron via adhesive Sax7/L1CAM-Sax3/Robo interactions. ALA axons run along the lateral nerve cord and express the adhesion protein Sax7/L1CAM. Primary PVD dendrites, on the other hand, express Sax3/Robo and project along ALA axons (Ramirez-Suarez et al., 2019). Sax7/L1CAM co-immunoprecipitated with tagged Sax3/Robo proteins, and mutual recognition in vivo caused morphological changes in PVD dendritic growth cones and re-oriented their actin cytoskeleton (Chen et al., 2019). Substrate adhesion therefore correlated well with structural changes in the underlying cytoskeleton. Such substrate-mediated cytoskeleton remodeling 
has been observed in various neuronal motility systems (Suter and Forscher, 2000; Myers et al., 2011). Reorganization is usually mediated by transmembrane receptors and specialized cytoplasmic adaptor proteins thought to function as molecular clutches (Lin and Forscher, 1995; Bard et al., 2008; Myers et al., 2011). Dynamic linkage of guidance receptors to filopodial actin flow is, therefore, a possible scenario for the conversion of attractive cues into forward movements or growth cone turning.

Substrate-derived attractants also play an important role during Drosophila development. There is accumulating evidence that Sidestep (Side) marks permissive substrates for outgrowing motor axons (Figure 1C). Side is a transmembrane protein of the immunoglobulin family and attracts motor axons (Sink et al., 2001; de Jong et al., 2005). Motor axons pioneering the intersegmental nerve (ISN) leave the ventral nerve cord by growing along an array of Side-expressing cells (Siebert et al., 2009). Once in the periphery, they fasciculate with Sidepositive, peripheral sensory axons that grow into the CNS. Although Side is difficult to detect in a subset of sensory axons, based on the location of the sensory clusters in the lateral body wall, major motor nerves could in principle reach their appropriate target regions by simply growing along sensory tracks followed by defasciculation into the muscle fields. Motor axons are firmly attached to sensory axons in wild-type embryos but show detachments in side mutants (Siebert et al., 2009). Beaten path Ia (Beat), also a member of the immunoglobulin family, is expressed in motor neurons and functions to detect Side (Fambrough and Goodman, 1996; Siebert et al., 2009). First, loss of beat leads to highly similar axon guidance errors and muscle innervation phenotypes as observed in side mutants (Fambrough and Goodman, 1996; Sink et al., 2001). A phenotype that is not increased in double mutants (Siebert et al., 2009). Second, Beat and Side interact with each other in S2 cell aggregations assays and in immunoprecipitation experiments (Siebert et al., 2009). Third, while Side is no longer detectable on peripheral nerves at the end of embryogenesis using Side-specific antibodies, it is constitutively expressed in beat mutants (Siebert et al., 2009). In fact, homozygous beat mutant embryos can be visually distinguished from heterozygous embryos based on Side expression, indicating that there is some sort of cross-regulation. And fourth, Side loses its ability to attract motor axons in beat mutants (Siebert et al., 2009). These results indicate that Beat on motor axons recognizes Side in substrates during the establishment of neuromuscular circuits.

Drosophila peripheral nerves express several axon guidance receptors of the immunoglobulin superfamily, but in direct comparisons, Side seems to be most potent in attracting motor

\section{REFERENCES}

Affolter, M., and Caussinus, E. (2008). Tracheal branching morphogenesis in Drosophila: new insights into cell behaviour and organ architecture. Development 135, 2055-2064. doi: 10.1242/dev.014498

Amack, J. D., and Manning, M. L. (2012). Knowing the boundaries: extending the differential adhesion hypothesis in embryonic cell sorting. Science 338, 212-215. doi: 10.1126/science. 1223953 axons (Kinold et al., 2018). In fact, overexpression of Side, but not the homophilic adhesion proteins Fasciclin II or Neuroglian, in developing muscles irreversibly attracted dorsally-directed ISN motor axons to ventral and lateral muscle precursors (Kinold et al., 2018). The Drosophila genome contains several paralogs of Beat and Side, and recent interactome assays revealed that several family members form ligand-receptor pairs or are expressed in synaptic partner neurons (Özkan et al., 2013; Tan et al., 2015). In addition, the expression patterns of some proteins in the Side family are consistent with a possible role as substratebased cues (Li et al., 2017). Thus, proteins of the Beat and Side family might mediate contact attraction of various pathways, highlighting the importance of the spatiotemporal expression pattern and the subcellular localization of the proteins during axon guidance by attraction.

\section{CONCLUSION}

Labeling cell surfaces along migratory routes with potent attractants might be a powerful means to steer cells and axons, irrespective of the nature of other factors nearby. Differential attraction, that is, preferred attraction to designated substrates over their surroundings, might actually be sufficient to guide cells and axons. However, I emphasize that due to space constraints other aspects of axon guidance and cell migration, such as repellents (Kolodkin and Tessier-Lavigne, 2011; Seiradake et al., 2016) or the relevance of birth order-dependent axon organization (Kulkarni et al., 2016), axon branching (Kalil and Dent, 2014) and new developmental rules for axon sorting (Langen et al., 2015) could not be covered. Largely unresolved remain also the signaling mechanisms downstream of adhesion receptors and the integration of attractive and repulsive cues in the growth cone. A highly interesting point is the consequence of axon guidance errors for adult locomotion and behavior. While several axon guidance diseases have been identified in humans (Engle, 2010), there are still only a few examples of inherited mutations affecting the wiring of the musculoskeletal system.

\section{AUTHOR CONTRIBUTIONS}

Concept, figure and writing by HA.

\section{FUNDING}

This work was supported by a grant from the Deutsche Forschungsgemeinschaft to HA (DFG Ab116/5-1).

Bard, L., Boscher, C., Lambert, M., Mège, R. M., Choquet, D., and Thoumine, O (2008). A molecular clutch between the actin flow and N-cadherin adhesions drives growth cone migration. J. Neurosci. 28, 5879-5890. doi: 10.1523/JNEUROSCI.5331-07.2008

Bate, C. M. (1976). Pioneer neurones in an insect embryo. Nature 260, 54-56. doi: $10.1038 / 260054 \mathrm{a} 0$

Bhattacharyya, B. J., Banisadr, G., Jung, H., Ren, D., Cronshaw, D. G., Zou, Y., et al. (2008). The chemokine stromal cell-derived factor-1 regulates GABAergic 
inputs to neural progenitors in the postnatal dentate gyrus. J. Neurosci. 28, 6720-6730. doi: 10.1523/JNEUROSCI.1677-08.2008

Bin, J. M., Han, D., Lai Wing Sun, K., Croteau, L. P., Dumontier, E., Cloutier, J. F., et al. (2015). Complete loss of netrin-1 results in embryonic lethality and severe axon guidance defects without increased neural cell death. Cell Rep. 12, 1099-1106. doi: 10.1016/j.celrep.2015.07.028

Boldajipour, B., Mahabaleshwar, H., Kardash, E., Reichman-Fried, M., Blaser, H., Minina, S., et al. (2008). Control of chemokine-guided cell migration by ligand sequestration. Cell 132, 463-473. doi: 10.1016/j.cell.2007.12.034

Bonhoeffer, F., and Huf, J. (1980). Recognition of cell types by axonal growth cones in vitro. Nature 288, 162-164. doi: 10.1038/288162a0

Brankatschk, M., and Dickson, B. J. (2006). Netrins guide Drosophila commissural axons at short range. Nat. Neurosci. 9, 188-194. doi: 10.1038/nn1625

Caussinus, E., Colombelli, J., and Affolter, M. (2008). Tip-cell migration controls stalk-cell intercalation during Drosophila tracheal tube elongation. Curr. Biol. 18, 1727-1734. doi: 10.1016/j.cub.2008.10.062

Chalasani, S. H., Sabelko, K. A., Sunshine, M. J., Littman, D. R., and Raper, J. A. (2003). A chemokine, SDF-1, reduces the effectiveness of multiple axonal repellents and is required for normal axon pathfinding. J. Neurosci. 23, 1360-1371. doi: 10.1523/JNEUROSCI.23-04-01360.2003

Chen, C. H., Hsu, H. W., Chang, Y. H., and Pan, C. L. (2019). Adhesive L1CAM-robo signaling aligns growth cone F-actin dynamics to promote axon-dendrite fasciculation in C. elegans. Dev. Cell 48, 215-228. doi: 10.1016/j. devcel.2018.10.028

David, N. B., Sapede, D., Saint-Etienne, L., Thisse, C., Thisse, B., DamblyChaudiere, C., et al. (2002). Molecular basis of cell migration in the fish lateral line: role of the chemokine receptor CXCR4 and of its ligand, SDF1. Proc. Natl. Acad. Sci. U S A 99, 16297-16302. doi: 10.1073/pnas.252339399

de Jong, S., Cavallo, J. A., Rios, C. D., Dworak, H. A., and Sink, H. (2005). Target recognition and synaptogenesis by motor axons: responses to the sidestep protein. Int. J. Dev. Neurosci. 23, 397-410. doi: 10.1016/j.ijdevneu.2004.10.002

Dickson, B. J. (2002). Molecular mechanisms of axon guidance. Science 298, 1959-1964. doi: 10.1126/science. 1072165

Doitsidou, M., Reichman-Fried, M., Stebler, J., Köprunner, M., Dörries, J., Meyer, D., et al. (2002). Guidance of primordial germ cell migration by the chemokine SDF-1. Cell 111, 647-659. doi: 10.1016/s0092-8674(02)01135-2

Dominici, C., Moreno-Bravo, J. A., Puiggros, S. R., Rappeneau, Q., Rama, N., Vieugue, P., et al. (2017). Floor-plate-derived netrin-1 is dispensable for commissural axon guidance. Nature 545, 350-354. doi: 10.1038/nature22331

Du, L., Zhou, A., Patel, A., Rao, M., Anderson, K., and Roy, S. (2017). Unique patterns of organization and migration of FGF-expressing cells during Drosophila morphogenesis. Dev. Biol. 427, 35-48. doi: 10.1016/j.ydbio.2017. 05.009

Engle, E. C. (2010). Human genetic disorders of axon guidance. Cold Spring Harb. Perspect. Biol. 2:a001784. doi: 10.1101/cshperspect.a001784

Fambrough, D., and Goodman, C. S. (1996). The Drosophila beaten path gene encodes a novel secreted protein that regulates defasciculation at motor axon choice points. Cell 87, 1049-1058. doi: 10.1016/s0092-8674(00)81799-7

Friedl, P., and Gilmour, D. (2009). Collective cell migration in morphogenesis, regeneration and cancer. Nat. Rev. Mol. Cell Biol. 10, 445-457. doi: $10.1038 / \mathrm{nrm} 2720$

Ghysen, A., and Dambly-Chaudière, C. (2004). Development of the zebrafish lateral line. Curr Opin Neurobiol 14, 67-73. doi: 10.1016/j.conb.2004.01.012

Gilmour, D., Knaut, H., Maischein, H. M., and Nüsslein-Volhard, C. (2004). Towing of sensory axons by their migrating target cells in vivo. Nat. Neurosci. 7, 491-492. doi: 10.1038/nn1235

Goodman, C. S., Bastiani, M. J., Doe, C. Q., du Lac, S., Helfand, S. L., Kuwada, J. Y., et al. (1984). Cell recognition during neuronal development. Science 225, 1271-1279. doi: 10.1126/science.6474176

Goodman, C. S., Raper, J. A., Ho, R. K., and Chang, S. (1982). "Pathfinding by neuronal growth cones in grasshopper embryos," in Developmental Order: Its Origin and Regulation, eds S. Subtelny and P. B. Green (New York, NY: Alan R. Liss Inc.), 275-316.

Gottlieb, D. I. (1980). The 'blueprint hypothesis' of axon guidance. Nature 283:428. doi: $10.1038 / 283428 \mathrm{a} 0$

Haas, P., and Gilmour, D. (2006). Chemokine signaling mediates self-organizing tissue migration in the zebrafish lateral line. Dev. Cell 10, 673-680. doi: 10.1016/j.devcel.2006.02.019
Hammarback, J. A., Palm, S. L., Furcht, L. T., and Letourneau, P. C. (1985). Guidance of neurite outgrowth by pathways of substratum-adsorbed laminin. J. Neurosci. Res. 13, 213-220. doi: 10.1002/jnr.490130115

Harrison, R. G. (1907). Experiments in transplanting limbs and their bearing upon the problems of the development of nerves. J. Exp. Zool. 4, 239-281. doi: 10.1002/jez.1400040205

Harrison, R. G. (1910). The outgrowth of the nerve fiber as a mode of protoplasmic movement. J. Exp. Zool. 9, 787-846. doi: 10.1002/jez.1400090405

Kalil, K., and Dent, E. W. (2014). Branch management: mechanisms of axon branching in the developing vertebrate CNS. Nat. Rev. Neurosci. 15, 7-18. doi: $10.1038 / \mathrm{nrn} 3650$

Katz, M. J., and Lasek, R. J. (1978). Eyes transplanted to tadpole tails send axons rostrally in two spinal-cord tracts. Science 199, 202-204. doi: 10.1126/science. 619452

Katz, M. J., and Lasek, R. J. (1979). Substrate pathways which guide growing axons in Xenopus embryos. J. Comp. Neurol. 183, 817-831. doi: 10.1002/cne. 901830409

Kinold, J. C., Pfarr, C., and Aberle, H. (2018). Sidestep-induced neuromuscular miswiring causes severe locomotion defects in Drosophila larvae. Development 145:dev163279. doi: 10.1242/dev.163279

Knaut, H., Werz, C., Geisler, R., Nüsslein-Volhard, C., and Tübingen Screen Consortium. (2003). A zebrafish homologue of the chemokine receptor Cxcr4 is a germ-cell guidance receptor. Nature 421, 279-282. doi: 10.1038/nature01338

Kolodkin, A. L., and Tessier-Lavigne, M. (2011). Mechanisms and molecules of neuronal wiring: a primer. Cold Spring Harb. Perspect. Biol. 3:a001727. doi: $10.1101 /$ cshperspect.a001727

Kuhn, T. B., Williams, C. V., Dou, P., and Kater, S. B. (1998). Laminin directs growth cone navigation via two temporally and functionally distinct calcium signals. J. Neurosci. 18, 184-194. doi: 10.1523/JNEUROSCI.18-01-00184.1998

Kulkarni, A., Ertekin, D., Lee, C. H., and Hummel, T. (2016). Birth order dependent growth cone segregation determines synaptic layer identity in the Drosophila visual system. Elife 5:e13715. doi: 10.7554/eLife.13715

Langen, M., Agi, E., Altschuler, D. J., Wu, L. F., Altschuler, S. J., and Hiesinger, P. R. (2015). The developmental rules of neural superposition in Drosophila. Cell 162, 120-133. doi: 10.1016/j.cell.2015.05.055

Lemmon, V., Burden, S. M., Payne, H. R., Elmslie, G. J., and Hlavin, M. L. (1992). Neurite growth on different substrates: permissive versus instructive influences and the role of adhesive strength. J. Neurosci. 12, 818-826. doi: 10.1523/JNEUROSCI.12-03-00818.1992

Letourneau, P. C. (1975a). Cell-to-substratum adhesion and guidance of axonal elongation. Dev. Biol. 44, 92-101. doi: 10.1016/0012-1606(75)90379-6

Letourneau, P. C. (1975b). Possible roles for cell-to-substratum adhesion in neuronal morphogenesis. Dev. Biol. 44, 77-91. doi: 10.1016/00121606(75)90378-4

Lewellis, S. W., and Knaut, H. (2012). Attractive guidance: how the chemokine SDF1/CXCL12 guides different cells to different locations. Semin. Cell Dev. Biol. 23, 333-340. doi: 10.1016/j.semcdb.2012.03.009

Lewellis, S. W., Nagelberg, D., Subedi, A., Staton, A., LeBlanc, M., Giraldez, A., et al. (2013). Precise SDF1-mediated cell guidance is achieved through ligand clearance and microRNA-mediated decay. J. Cell Biol. 200, 337-355. doi: $10.1083 /$ jcb. 201207099

Li, H., Watson, A., Olechwier, A., Anaya, M., Sorooshyari, S. K., Harnett, D. P., et al. (2017). Deconstruction of the Beaten path-Sidestep interaction network provides insights into neuromuscular system development. Elife 6:e28111. doi: 10.7554/elife.28111

Lin, C. H., and Forscher, P. (1995). Growth cone advance is inversely proportional to retrograde F-actin flow. Neuron 14, 763-771. doi: 10.1016/08966273(95) $90220-1$

Miller, J. T., Bartley, J. H., Wimborne, H. J., Walker, A. L., Hess, D. C., Hill, W. D., et al. (2005). The neuroblast and angioblast chemotaxic factor SDF-1 (CXCL12) expression is briefly up regulated by reactive astrocytes in brain following neonatal hypoxic-ischemic injury. BMC Neurosci. 6:63. doi: 10.3389/fphys. 2019.00023

Moore, S. W., Biais, N., and Sheetz, M. P. (2009). Traction on immobilized netrin-1 is sufficient to reorient axons. Science 325:166. doi: 10.1126/science.1173851

Moreno-Bravo, J. A., Roig Puiggros, S., Mehlen, P., and Chedotal, A. (2019). Synergistic activity of floor-plate- and ventricular-zone-derived netrin-1 in 
spinal cord commissural axon guidance. Neuron 101, 625-634. doi: 10.1016/j. neuron.2018.12.024

Myers, J. P., Santiago-Medina, M., and Gomez, T. M. (2011). Regulation of axonal outgrowth and pathfinding by integrin-ECM interactions. Dev. Neurobiol. 71, 901-923. doi: 10.1002/dneu.20931

Oakley, R. A., and Tosney, K. W. (1993). Contact-mediated mechanisms of motor axon segmentation. J. Neurosci. 13, 3773-3792. doi: 10.1523/JNEUROSCI.1309-03773.1993

O'Connor, T. P., Duerr, J. S., and Bentley, D. (1990). Pioneer growth cone steering decisions mediated by single filopodial contacts in situ. J. Neurosci. 10, 3935-3946. doi: 10.1523/JNEUROSCI.10-12-03935.1990

Özkan, E., Carrillo, R. A., Eastman, C. L., Weiszmann, R., Waghray, D., Johnson, K. G., et al. (2013). An extracellular interactome of immunoglobulin and LRR proteins reveals receptor-ligand networks. Cell 154, 228-239. doi: 10.1016/j.cell.2013.06.006

Peled, A., Petit, I., Kollet, O., Magid, M., Ponomaryov, T., Byk, T., et al. (1999). Dependence of human stem cell engraftment and repopulation of NOD/SCID mice on CXCR4. Science 283, 845-848. doi: 10.1126/science.283.5403.845

Pocha, S. M., and Montell, D. J. (2014). Cellular and molecular mechanisms of single and collective cell migrations in Drosophila: themes and variations. Annu. Rev. Genet. 48, 295-318. doi: 10.1146/annurev-genet-120213-092218

Ramirez-Suarez, N. J., Belalcazar, H. M., Salazar, C. J., Beyaz, B., Raja, B., Nguyen, K. C. Q., et al. (2019). Axon-dependent patterning and maintenance of somatosensory dendritic arbors. Dev. Cell 48, 229.e4-244.e4. doi: 10.1016/j. devcel.2018.12.015

Ramon Y Cajal, S. (1890). Sobre la aparición de las expansiones celulares en la médula embrionaria. Gac Sanit Barc 12, 413-419.

Raper, J., and Mason, C. (2010). Cellular strategies of axonal pathfinding. Cold Spring Harb. Perspect. Biol. 2:a001933. doi: 10.1101/cshperspect.a001933

Reiss, K., Mentlein, R., Sievers, J., and Hartmann, D. (2002). Stromal cell-derived factor 1 is secreted by meningeal cells and acts as chemotactic factor on neuronal stem cells of the cerebellar external granular layer. Neuroscience 115, 295-305. doi: 10.1016/s0306-4522(02)00307-x

Schwabe, T., Borycz, J. A., Meinertzhagen, I. A., and Clandinin, T. R. (2014). Differential adhesion determines the organization of synaptic fascicles in the Drosophila visual system. Curr. Biol. 24, 1304-1313. doi: 10.1016/j.cub.2014. 04.047

Seiradake, E., Jones, E. Y., and Klein, R. (2016). Structural perspectives on axon guidance. Annu. Rev. Cell Dev. Biol. 32, 577-608. doi: 10.1146/annurev-cellbio111315-125008

Serafini, T., Colamarino, S. A., Leonardo, E. D., Wang, H., Beddington, R., Skarnes, W. C., et al. (1996). Netrin-1 is required for commissural axon guidance in the developing vertebrate nervous system. Cell 87, 1001-1014. doi: 10.1016/s0092-8674(00)81795-x

Siebert, M., Banovic, D., Goellner, B., and Aberle, H. (2009). Drosophila motor axons recognize and follow a Sidestep-labeled substrate pathway to reach their target fields. Genes Dev. 23, 1052-1062. doi: 10.1101/gad.520509

Singer, M., Nordlander, R. H., and Egar, M. (1979). Axonal guidance during embryogenesis and regeneration in the spinal cord of the newt: the blueprint hypothesis of neuronal pathway patterning. J. Comp. Neurol. 185, 1-21. doi: $10.1002 / \mathrm{cne} .901850102$
Sink, H., Rehm, E. J., Richstone, L., Bulls, Y. M., and Goodman, C. S. (2001). sidestep encodes a target-derived attractant essential for motor axon guidance in Drosophila. Cell 105, 57-67. doi: 10.1016/s0092-8674(01) 00296-3

Sohr, A., Du, L., Wang, R., Lin, L., and Roy, S. (2019). Drosophila FGF cleavage is required for efficient intracellular sorting and intercellular dispersal. J. Cell Biol. 218, 1653-1669. doi: 10.1083/jcb.201810138

Sperry, R. W. (1963). Chemoaffinity in the orderly growth of nerve fiber patterns and connections. Proc. Natl. Acad. Sci. U S A 50, 703-710. doi: 10.1073/pnas. 50.4.703

Suter, D. M., and Forscher, P. (2000). Substrate-cytoskeletal coupling as a mechanism for the regulation of growth cone motility and guidance. J. Neurobiol. 44, 97-113.

Sutherland, D., Samakovlis, C., and Krasnow, M. A. (1996). branchless encodes a Drosophila FGF homolog that controls tracheal cell migration and the pattern of branching. Cell 87, 1091-1101. doi: 10.1016/s0092-8674(00) 81803-6

Szabó, A., and Mayor, R. (2018). Mechanisms of neural crest migration. Annu. Rev. Genet. 52, 43-63. doi: 10.1146/annurev-genet-120417-031559

Tan, L., Zhang, K. X., Pecot, M. Y., Nagarkar-Jaiswal, S., Lee, P. T., Takemura, S. Y., et al. (2015). Ig superfamily ligand receptor pairs expressed in synaptic partners in Drosophila. Cell 163, 1756-1769. doi: 10.1016/j.cell.2015.11.021

Tessier-Lavigne, M., and Goodman, C. S. (1996). The molecular biology of axon guidance. Science 274, 1123-1133. doi: 10.1126/science.274.5290.1123

Varadarajan, S. G., Kong, J. H., Phan, K. D., Kao, T. J., Panaitof, S. C., Cardin, J., et al. (2017). Netrin1 produced by neural progenitors, not floor plate cells, is required for axon guidance in the spinal cord. Neuron 94, 790.e3-799.e3. doi: 10.1016/j.neuron.2017.03.007

von Philipsborn, A., and Bastmeyer, M. (2007). Mechanisms of gradient detection: a comparison of axon pathfinding with eukaryotic cell migration. Int. Rev. Cytol. 263, 1-62. doi: 10.1016/s0074-7696(07)63001-0

Weiss, P. (1941). Nerve patterns: the mechanics of nerve growth. Growth 5, 163-203.

Wu, Z., Makihara, S., Yam, P. T., Teo, S., Renier, N., Balekoglu, N., et al. (2019). Long-range guidance of spinal commissural axons by netrin 1 and sonic hedgehog from midline floor plate cells. Neuron 101, 635-647. doi: 10.1016/j. neuron.2018.12.025

Yung, A. R., Nishitani, A. M., and Goodrich, L. V. (2015). Phenotypic analysis of mice completely lacking netrin 1. Development 142, 3686-3691. doi: $10.1242 /$ dev.128942

Conflict of Interest Statement: The author declares that the research was conducted in the absence of any commercial or financial relationships that could be construed as a potential conflict of interest.

Copyright (C) 2019 Aberle. This is an open-access article distributed under the terms of the Creative Commons Attribution License (CC BY). The use, distribution or reproduction in other forums is permitted, provided the original author(s) and the copyright owner(s) are credited and that the original publication in this journal is cited, in accordance with accepted academic practice. No use, distribution or reproduction is permitted which does not comply with these terms. 